\title{
Balancing theory with practice: studying the rebound effect
}

\author{
Ian G. Hamilton
}

\section{The Rebound Effect in Home Heating: A guide for policymakers and practitioners}

Ray Galvin

BRI Series, Earthscan from Routledge, Abingdon, Oxon, UK 2016

ISBN 978138788350

"In theory there is no difference between theory and practice. In practice there is. (attributed to Jan L. A. van de Snepscheut, Yogi Berra, among others)"

According to the International Energy Agency (IEA), residential buildings are estimated to account for $74 \%$ of global building energy use, of which $30 \%$ is estimated to be used for space heating by the IEA publication entitled Energy Efficiency Market Report (2015, p. 69). The IEA also estimates that space heating demand in the global residential stock has grown by only 5\% between 2002 and 2012, despite increases in total populations, households, incomes and expectations of thermal comfort. Set against greenhouse gas emissions reduction targets, countries in colder climates have directed polices to improving the energy performance of their building stock with the aim of reducing heating energy demand. Energy policy directed at the residential stock has sought to manage and shift energy demand through changes in: occupant practices (e.g., informing how and why one should use energy more efficiently), operations (e.g., heating controls or feedback information), building fabric performance (e.g., insulation and draught exclusion); and heating and ventilation technologies (e.g., high-efficiency boilers and heat recovery).

Despite headline figures of reductions in the intensity of energy demand as noted by the IEA (p. 58), there is an emerging body of evidence that shows many energy-efficiency retrofit policies are not as effective as expected (e.g., I. G. Hamilton et al., 'Energy efficiency uptake and energy savings in English houses: A cohort study'. Energy and Buildings 2016, 259-276). Physicists, engineers, building and energy researchers, and policy-makers all face the same consternating fact that despite considerable study, monitoring, modelling and policies, there remains a persistent gap between both actual energy demand and predicted demand in residential buildings. And, related to this issue, energy-efficiency intervention rarely ever saves as much energy as estimated, even when using some of the most sophisticated models.

The residential housing stock in most countries is a heterogeneous cohort with considerable variation in construction techniques, energy performance, heating technologies, household characteristics, energy needs and many others. Yet many building and energy experts (researchers, practitioners and policy-makers) feel that we know what are the major drivers of home space-heating energy demand. This knowledge is often drawn from our experiences of living in homes (as compared with the nonresidential sector which we may have only limited knowledge or experience of). These drivers are 
often (very) broadly themed into a number of intersecting and interacting characteristics, namely: the physical and engineered building system, occupant and the related socio-economic, environmental conditions, and socio-cultural and institutional influences. However, despite our knowledge / experience of these drivers, most models struggle to accurately predict accurately residential energy demand at the stock (or sub-stock) level. This challenge has meant that a considerable gap exists when comparing the model results with actual energy demand. Why does this gap persist in the research and policy field between how energy is modelled and actual energy savings? And what does this gap really mean?

The Rebound Effect in Home Heating by Dr Ray Galvin is a new book in the Building Research \& Information book series that aims to offer new interdisciplinary and transdisciplinary in-depth coverings, which this book is among the first. Galvin seeks to offer a practical guide for policy-makers and practitioners in understanding how rebound affects home heating. The aim of the book is to offer its audience a deeper understanding of the rebound effect, practical methods for understanding and analysing it, and the implications it might have in both research and policy. This respectfully slim book contains a well- selected set of chapters covering: an introduction to the rebound effect as it applies to domestic heating, a discussion of the causes of rebound effect as under- stood by various disciplines; methods for estimating the effect on home heating energy demand; the relationship between rebound and fuel poverty and also low-energy housing; along with a consideration about how the effect is seen in non-residential buildings. There is considerable effort given to providing the mathematical basis of the rebound effect, which for those interested in detailed proofs and explanations is a welcome addition.

Historically, economists offered the most research and guidance on the energy-demand rebound effect, and as a result the problem has tended to be under- stood in those terms. Galvin uses a wellknown definition of the rebound effect as occurring 'where an energy efficiency increase leads to an increase in the consumption of energy services' (p. 7). In the opening chapter he outlines how the rebound effect is different for home heating than it is for other services or goods. For example, he states that there are reasonable limits to how much energy might typically be used for a given residential service, and that the rebound effect is greatest among those who have the highest need. For those working in the energy and buildings discipline, this seems appropriate. The chapter ends with a number of social and technical characteristics that are important for energy-using services. Galvin ultimately leads the reader to an economic indicator of rebound, known as elasticity, alongside two engineering - physics approaches.

In covering the causes of rebound, Galvin outlines those influences that may result in its effect in home heating, including: comfort-taking, lifestyle changes, human - technology interaction failures, technology miscalculation, technical failures and building model- ling miscalculation. In summarizing these influences, Galvin states that 'attempts to divide the causes of over-consumption into human and technical elements are misleading, and therefore a single figure for the rebound is appropriate' ( $\mathrm{p}$. 23). In this instance, however, I would tend to disagree. In the event that over-consumption is a real condition, it would be preferable to attribute the consumption to specific causes in order to develop interventions and policies to manage the consumption. However, this would imply having the means to analyse the condition with appropriate studies and data, and so Galvin outlines a pragmatic 
approach for the time being. Part of the problem, as Galvin outlines, is that for the most part, basic information about energy demand in buildings is simply lacking. For example, as research by A. J. Summerfield and R. J. Lowe, 'Challenges and future directions for energy and buildings research' (Building Research $\mathcal{E}$ Information, 2012, pp. 391 - 400), attests, trends and patterns along with simple descriptions of population and stock segmentations are limited or do not exist. Without even basic descriptions and agreed metrics of energy demand in buildings, developing a policy frame- work to achieve change in demand is undermined by the general lack of a strong evidence base and a misunderstanding of consequential drivers. Historically, this lack of evidence is related to the prioritization of funding, the transient nature of academic research and a dearth of observed data, and therefore reliance on models that are often poorly informed or outdated, as R. J. Lowe and T. Oreszczyn discuss in 'Regulatory standards and barriers to improved performance for housing' (Energy Policy, 2008, 4475 -4481). As a result, unfit models continue to be used to model energy demand, the effect of which is estimates of energy demand that fall widely away from what is measured, which Galvin (along with Sunikka-Blank - see below) calls 'prebound' .

The idea underlying the prebound condition is that the dwelling uses less than estimated prior to a retrofit, which then leads to lower-than-expected savings as a result of the modelling. For further details, see M. Sunikka-Blank and R. Galvin, 'Introducing the prebound effect: The gap between performance and actual energy consumption' (Building Research \& Information, 2012, 260 - 273). Because less energy is initially used, there is less energy to save, which leads to a rebound. Therefore, prebound measures the energy that cannot be saved. In many ways, this concept is reflecting that energy prediction models simply do not properly capture the actual drivers of energy use. While many recognize that physics - engineering-based models do not tell the full story and that they are often based on limited real-world observations, their results are at risk of being over-interpreted and given too much weight, particularly in the policy sphere.

Why is there a gap in heating demand modelling in the residential sector? If one considers what building physics - engineering-based models include, it is known they are often limited to the physical materials of the building and the engineered systems within. While the physics are underpinned by laws, their application is not. What often happens is that crude assumptions are needed on a whole host of both physics and engineering system features in order to overcome the paralysis of otherwise needing a rocket-grade sensory laboratory. The field needs much better models, not only those that can predict energy demand but also those that are more capable of predicting change in energy demand (related but distinct issues). It is unrealistic to expect that steady-state models would be robust to estimate the change in energy demand following an efficiency retrofit, particularly as the act of retrofitting aims to affect how occupants experience (and use) their home. But underlying better models will be better data, for which more effort is needed to procure and access better energy and buildings data. The implication of misusing or having poorly calibrated models could be significant impacts on both policies and energy-efficiency programmes.

In chapter 4, on different methods for estimating the rebound effect, Galvin selects the economic measure of 'elasticity' as his preferred method. His thesis is that this method has four main advantages, i.e., it is adaptable from other sectors, mathematically robust, can be modelled using a variety of methods and is well recognized across disciplines. In cases where this method is not 
appropriate, he suggests using physics - engineering modelling methods combined with actual data through an analysis of the 'energy performance gap' and the 'energy demand deficit'. These latter methods use existing building simulation models along with measures of actual consumption to characterize the gap between estimated and actual energy demand, and demand before and after a retrofit. Within this section a number of very useful case studies are offered. One of the concluding points the author makes is the importance of having actual and calculated consumption for a large number of dwellings so as to apply these methods within a setting. This places pressure on policymakers to develop an evidence base that uses empirically derived data alongside models built on a stronger data foundation. The implication of not having this source is that future policies are developed on theoretical positions alone.

There is a great need for a strong theoretical basis to understand how the rebound manifests itself within residential heating energy demand and for tools that can deal with this effect when analysing large-scale intervention programmes. Yet to date no intervention to reduce energy demand in buildings has been subjected to comprehensive empirical evaluation in any major developed country of the type or scale being proposed in many greenhouse gas (GHG)-abatement plans. As a result, the data, tools, systems and models used to support the design, implementation and evaluation of such interventions are absent or uncalibrated. This therefore leaves a significant gap in an under- standing of what the direct and indirect effects of a policy or technology has in practice, as compared with assumptions drawn from models. The theoretical understanding of social and technical factors that influence energy demand remains largely underdeveloped. It is these gaps in our approach that lead to gaps in how we understand, model and manage energy demand in the residential stock. Take, for example, the Passive House, which Galvin describes in detail in chapter 5, which research shows that the energy - performance gap is much greater than in equivalent non- low-energy houses. This does suggest that the models used to predict energy demand are valid only to notional estimates of demand and do not capture real activities inside the home.

Emerging throughout the book, but explicitly considered within the final chapter 8, Galvin offers an answer to part of why the rebound effect persists. The answer is that heating energy demand needs to be under- stood from a socio-technical perspective, rather than the purely economic or technical perspectives.

Economic and technological approaches have been criticized for treating the occupant as either an autonomous rational being or as a functioning component in a system rather than attempting to reflect his or her social practices as fundamental drivers of energy demand. Energy-demand research from the engineering and physics perspective has grown greatly over the past two decades, most certainly influenced by the availability of better computers and simulation models, but also the general lack of data. This technical paradigm has placed buildings and their accompanying technologies and physical processes at the centre of describing energy demand - often from a disaggregated (i.e., building bottom-up) level. This approach is generally technologically focused, even when including occupants as part of the system. These approaches are often used to examine specific technical problems and rely on models in the absence of empirical data. The approach attempts to incorporate users through further parameterization of uncertainty, but often lacks detail on the range of user practices that would capture these unknown traits. The failure of this approach in being able to identify and 
understand the key drivers of energy demand has led to various conceptual 'fixes' that attempt to mitigate the expectations of technical understanding.

Under the socio-technical paradigm, energy-demand practices include the behaviours and norms, personal beliefs and values, and understanding of social institutions; for a description, see L.

Lutzenhiser, 'Social and behavioral aspects of energy use' (Annual Review of Energy and the

Environment, 1993, 247 - 289). Where engineered systems historically viewed users as passive and with little formal feedback, the social model sees users as actively and unintentionally inter- acting with the energy system to 'demand' services. Socio-technical analysis places greater focus on under- standing the uncertainty around the user as part of the technological and physical system, e.g., by widening the sensitivity of the user inputs. This paradigm has attempted to understand the impact that users have on influencing energy demand and energy savings. This area has come to the fore in an attempt to explain why technical models that attempt to account for user interactions have been unable to predict 'actual' demand. Recently, the socio-technical perspective has been argued as a more constructive and inclusive approach to study energy use in buildings because it acknowledges the mutually codependent nature of social actors and technologies and the enmeshing of social activities and technological artefacts. It is this socio-technical approach that Galvin suggests should be more readily applied to answering the challenges faced when attempting to measure and model the energy rebound effect.

As the book's cover suggests, those who would benefit most from the book are indeed practitioners and policy-makers looking to get a deeper understanding of the rebound effect, methods of measurement, and suggestions on how to manage and mitigate the effect in home heating modelling and policies. The illustrations and equations offered are easy to understand and helpfully explained in the text. This book is a welcome addition to an under-studied issue within the home heating literature.

\section{ORCID}

Ian G. Hamilton http:/ / orcid.org/ 0000-0003-2582- 2361

Ian G. Hamilton

University College London, UK e-mail: i.hamilton@ucl.ac.uk

(C) 2016, Ian G. Hamilton 